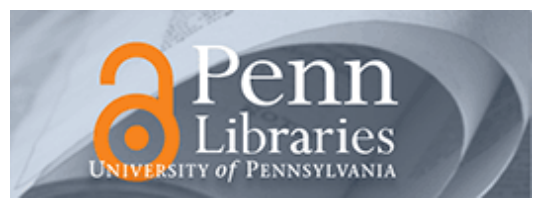

University of Pennsylvania

ScholarlyCommons

$1-1-2005$

\title{
A Theoretical Model to Explain the Overrepresentation of College Men among Campus Judicial Offenders: Implications for Campus Administrators
}

Shaun R. Harper, Ph.D.

University of Pennsylvania, sharper1@upenn.edu

Frank Harris III

San Diego State University

Kenechukwu (K.C.) Mmeje

University of Southern California

Follow this and additional works at: https://repository.upenn.edu/gse_pubs

Part of the Education Commons

\section{Recommended Citation (OVERRIDE)}

Harper, S. R., \& Kimbrough, W. M. Staffing practices, professional preparation trends, and demographics among student affairs administrators at HBCUs: Implications from a national study. NASAP Journal, 8(1), 8-25.

\section{Suggested Citation:}

Harper, S. R., \& Kimbrough, W. M. Staffing practices, professional preparation trends, and demographics among student affairs administrators at HBCUs: Implications from a national study. NASPA Journal, 8(1), 8-25.

This paper is posted at ScholarlyCommons. https://repository.upenn.edu/gse_pubs/203

For more information, please contact repository@pobox.upenn.edu. 


\title{
A Theoretical Model to Explain the Overrepresentation of College Men among Campus Judicial Offenders: Implications for Campus Administrators
}

\author{
Abstract \\ As is the case in most $\mathrm{K}-12$ schools, male students, in comparison to their female counterparts, \\ disproportionately violate policies and are sanctioned more often for violence and disruptive behaviors on \\ college and university campuses across the country. A theoretical model to explain this phenomenon is \\ proposed in this article. Specifically, a synthesis of existing literature and theories from sociology, \\ psychology, men's studies, and education resulted in the identification of six acute variables that explain \\ male overrepresentation among campus judicial offenders. While each component of the model is \\ thoroughly explained, insight into interactions among the six variables is also offered. Practical \\ implications for campus administrators who are interested in minimizing violence and disruptive \\ behaviors among college men conclude the article. \\ Disciplines \\ Education

\section{Comments} \\ Suggested Citation: \\ Harper, S. R., \& Kimbrough, W. M. Staffing practices, professional preparation trends, and demographics \\ among student affairs administrators at HBCUs: Implications from a national study. NASPA Journal, 8(1), \\ 8-25.
}




\title{
A Theoretical Model to Explain the Overrepresentation of College Men among Campus Judicial Offenders: Implications for Campus Administrators
}

\author{
Shaun R. Harper \\ Frank Harris III \\ Kenechukwu (K.C.) Mmeje
}

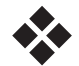

As is the case in most K-12 schools, male students, in comparison to their female counterparts, disproportionately violate policies and are sanctioned more often for violence and disruptive behaviors on college and university campuses across the country. A theoretical model to explain this phenomenon is proposed in this article. Specifically, a synthesis of existing literature and theories from sociology, psychology, men's studies, and education resulted in the identification of six acute variables that explain male overrepresentation among campus judicial offenders. While each component of the model is thoroughly
\end{abstract}

Shaun R. Harper is an assistant professor and research associate in the Center for the Study of Higher Education at The Pennsylvania State University. Frank Harris III is the associate director of the Center for Urban Education and a doctoral candidate in Higher Education Administration at the University of Southern California, Rossier School of Education. Kenechukwu (K.C.) Mmeje is the assistant director of the Office of Student Judicial Affairs and Community Standards at the University of Southern California. 
explained, insight into interactions among the six variables is also offered. Practical implications for campus administrators who are interested in minimizing violence and disruptive behaviors among college men conclude the article.

In his classic text, The American College \& University, historian Frederick Rudolph (1990) cites numerous incidences of student misconduct and discipline throughout the lifespan of higher education. For instance, he describes the introduction of a disciplinary sanction at Harvard in 1718, where "a bad boy was made to kneel at the feet of his tutor, who proceeded to smack him sharply on the ear" (p. 27). Reportedly, incivility and disruptions have long ensued on most campuses, especially those with residence halls. Physical brawls, food fights, property destruction, underage drinking, arson, stoning, and even stabbing were among the early examples of student misconduct. Most institutions responded by developing strict conduct codes and articulating the consequences of inappropriate behavior. Over time, some institutions, including Harvard, relaxed their disciplinary codes and took a more developmental approach to sanctioning student offenders. In an address to the faculty, former Harvard President Jared Sparks (as cited in Rudolph, 1990) pleaded, "Oh gentlemen, let the boys alone" (p. 107). It is interesting to note that most of the offenses described throughout Rudolph's book were overwhelmingly committed by male students—a trend that still persists on most contemporary college and university campuses.

Limited theoretical insight has been offered into the reasons why college men violate rules and commit acts that lead to disciplinary consequences. Van Kuren and Creamer (1989) noted that existing studies of student judicial issues were disproportionately focused on demographic and personality characteristics of offenders, not on the underlying causes of misbehavior. Dannells (1997) offers some characteristics of those who commit judicial offenses: "Most students who become involved in campus discipline difficulties are men, and most often they are younger, usually in their freshman and sophomore year" (p. 25). These male offenders, he notes, typically live on campus, are more likely to violate policies than are students who have positive feelings toward the institution, and are usually engaged in alcohol use or 
abuse at the time of the incident. Beyond this, little else is known about why college men engage in inappropriate acts, especially those that lead to judicial sanctions on their campuses. Moreover, the need for additional scholarship on the development and experiences of college men is consistently advocated throughout Kellom's (2004) New Directions for Student Services edited volume, Developing Effective Programs and Services for College Men.

In response to the call for additional inquiry on college men in general and judicial offenders in particular, a theoretical model that explains the disproportionate representation of male students in campus judicial processes is proposed in this article. Specifically, the impetus and underlying drivers of misbehavior, aggression, violence, and rulebreaking are explained. The model is based on a synthesis of existing literature and theories from sociology, psychology, men's studies, and education. Biological and heredity explanations for male misbehavior are not offered in this article, as the existing published research on masculinity almost exclusively considers these behaviors through a social constructivist lens. This perspective relates closely to the new psychology of men proposed by Levant (1996). "The new psychology of men views gender roles not as biological or even social givens, but as psychologically and socially constructed entities that bring certain advantages and disadvantages and, most importantly, can change" (p. 259). Social constructivism is later described in greater detail.

Following a detailed description of the theoretical model are practical implications for campus judicial affairs officers and student affairs administrators who are interested in minimizing violence and disruptive behaviors among college men. Before proceeding with the presentation of the theoretical model, it should be noted that not all behavioral expressions of masculinity are negative. Given that only a limited number of scholars have investigated positive aspects of masculinities (e.g., Harper, 2004; Mirande, 2004) and that this article focuses exclusively on judicial offenders, much of the literature and theoretical perspectives reviewed herein, appropriately by default, illuminate negative male behaviors. 


\section{Presentation of the Theoretical Model}

An interdisciplinary synthesis of existing literature and theories resulted in the identification of the following six variables that help explain male overrepresentation among campus judicial offenders: (1) precollege socialization, (2) male gender role conflict, (3) the social construction of masculinities, (4) the development of competence and self-efficacy, (5) context-bound gendered social norms, and (6) environmental ethos and corresponding behaviors. Each theoretical construct of the model in Figure 1, along with its specific relationship to misbehavior among college men, is described in this section; interactions among the six variables are discussed later in the article.

Figure 1

Theoretical Model of Misbehavior Among College Men

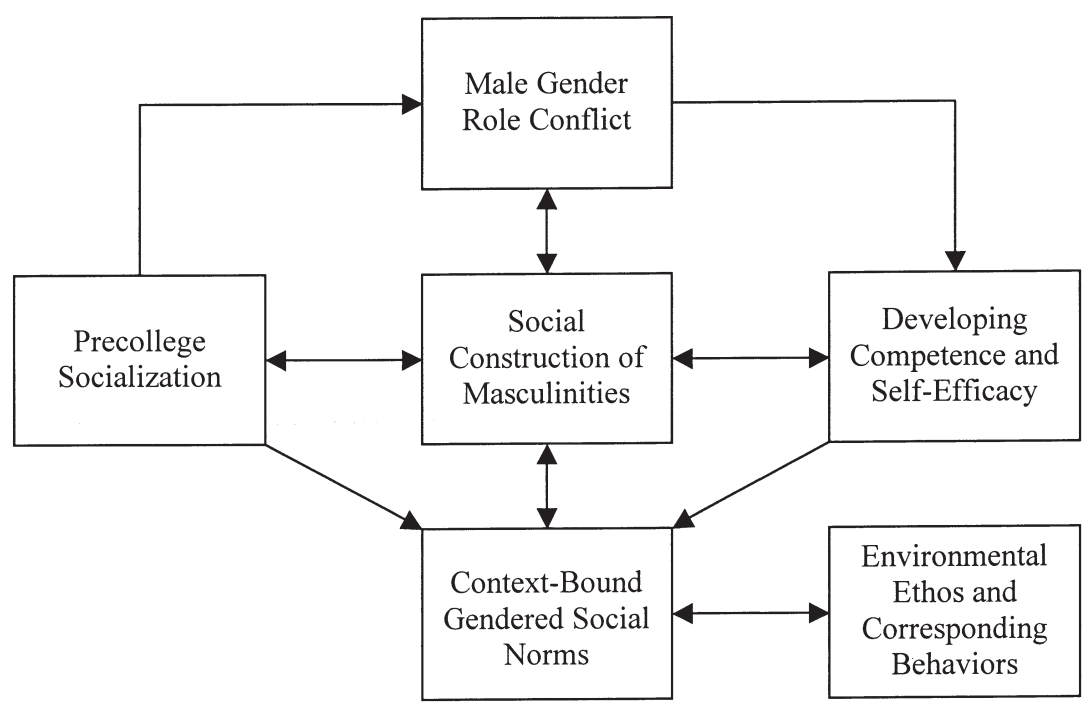

Precollege Socialization

The behaviors that men bring to college are often shaped by prior school experiences and home environments in which certain acts are deemed excusable and typical of boys. In many cases, parents, K-12 
teachers, and school administrators socialize boys and girls differently by posing an uncommon set of rules, sanctions, and standards regarding acceptable behavior. These socialization experiences begin at birth. One classic example of this was found in Smith and Lloyd's (1978) study, which involved 32 mothers and a bald infant. When the baby was dressed as a girl, the mothers spoke to 'her' differently; handled 'her' more affectionately; and selected softer toys for 'her,' such as dolls. A few days later, the exact same bald baby was dressed as a boy, but the same women treated 'him' completely different. For example, they selected a toy hammer for 'him' to play with instead of a soft stuffed animal or doll. Oftentimes, the toys that parents select for boys promote ruggedness, toughness, and violence. In fact, Askew and Ross (1988) maintain:

Girls are even encouraged to buy 'My First Sink,' and a 'head' on which they can practice putting [on] make-up and putting in curlers. Boys, on the other hand, quite predictably are shown playing with games, cars, mechanical toys, or space monsters. Most of these are toys taken straight from violent cartoons.... The main aim of playing with the toy is to battle it out with an opponent. (p. 7)

These toys and games, as well as the violent cartoons with which they are affiliated, are often infused with boys' definitions of self as they take on the characteristics of monsters, wrestlers, racecar drivers, and other physically active animated characters. These attributes are prominently displayed in their behaviors at home and in school, especially when other boys are present.

According to Gilbert and Gilbert (1998) and Head (1999), parents and teachers are more forgiving of behavioral problems among boys and accept the fact that "boys will be boys." Similarly, Harper (2004) asserts that parents "communicate messages of power, toughness, and competitiveness to their young sons. No father wants his son to grow up being a 'pussy,' 'sissy,' 'punk,' or 'softy'-terms commonly associated with boys and men who fail to live up to the traditional standards of masculinity" (p. 92). Gilbert and Gilbert also found that interests in combat, wrestling, and active play interferes with male students' abilities to concentrate in school and take their teachers (who are mostly female) seriously, which often results in classroom disruptions. 
Interestingly, boys are over four times more likely than girls in K-12 schools to be referred to the principal's office for disciplinary infractions, suspended, or subjected to corporal punishment (Gregory, 1996; Skiba, Michael, Nardo, \& Peterson, 2002). Despite this, boys are still socialized to believe that they are to be rough, tough, and rugged, even if it means getting into trouble at school (Mac an Ghaill, 1996).

College men who attended primary and secondary schools where male disruption and weak sanctions were the norm bring their prior socialization experiences to the postsecondary learning environment. Thus, some may presume that occasionally disobeying rules (without committing acts that are punishable in criminal court) is simply "what boys do" at school, and subsequently in college. Thus, some male undergraduates, to varying degrees, willingly disregard campus policies and risk being subjected to judicial sanctioning. Sudden freedom from parents and living on one's own only intensifies this problem.

Hong (2000) suggests there is a critical link between male students, socialization, and violence. College men bring aspects of prior socialization assumptions surrounding active play to the postsecondary setting. For example, they are more likely than their female counterparts to play with "toys" that are deemed unsafe and in violation of university policies. College men are more likely to be caught in possession of dangerous items (e.g., BB guns, firecrackers, paintball guns, knives) that violate university weapons policies. Despite knowing that these items constitute a policy violation and may result in severe sanctioning, some male undergraduates still choose to engage in play that involves their coveted toys. These toys, coupled with popular violent video games, enable male students to exert toughness, roughness, and perceivably harmless simulations of violence.

\section{Male Gender Role Conflict}

Conflict generally occurs when rigid and restrictive gender roles that are learned and reinforced during early socialization experiences result in personal restraint, devaluation, or violation of one's self or others (O'Neil, 1990). Male gender role conflict is a more specific concept that is used to describe the negative consequences associated with men's tendencies to conform to narrow socially constructed masculine 
roles (Good \& Wood, 1995; O'Neil \& Nadeau, 2004). Societal messages repeatedly indicate that men should become breadwinners for and protectors of their families, high-performers in competitive sports, and leaders and executives in the places at which they work (Harper, 2004). Failure to live up to these standards often results in conflict. Men's fear of femininity is also central to O'Neil's (1990) theory of male gender role conflict. This fear is described as "a strong, negative emotion associated with stereotypic feminine values, attitudes, and behaviors ... learned primarily in early childhood when gender identity is being formed by parents, peers, and societal values" (O'Neil, Helms, Gable, David, \& Wrightsman, 1986, p. 337). Other researchers have linked male gender role conflict with the unhealthy attitudes and risky behaviors exhibited by some college men, including violence, sexual assault and harassment, poor help-seeking tendencies, substance abuse, and homophobia (e.g., Davis, 2002; Good \& Wood, 1995; Ludeman, 2004). The propensity of these conflicts among college men indisputably contributes to their overrepresentation in campus judicial systems.

Male gender role conflict usually elicits a variety of emotional responses. Unfortunately, many undergraduate men are both unable and unwilling to productively unpack their emotions, and therefore resort to violent and aggressive behavior as a form of expression. For instance, a student may choose to release anger and frustration caused by romantic rejection through vandalizing a university building or destroying another student's property. This helps explain why college men commit the majority of vandalism and property destruction on college and university campuses.

Davis' (2002) study provides an assessment of socially prescribed gender roles among college men. Five key themes emerged in his qualitative study of ten White, traditional-aged male undergraduates. The importance of self expression is the first theme. Therein the participants described the conflicts that existed between their desires to express their authentic selves and the social constraints that limited their doing so. The second theme, code of communication caveats, is comprised of the following three sub-themes: (1) communication with women, (2) one-on-one communication with other men, and (3) nonverbal and side-by-side communication. Here, participants reflected upon the physical and interpersonal dynamics that characterized 
interactions with their same-sex peers, including the normality of humorous put-downs and jokes when groups of men interacted socially.

The third theme in Davis' study, fear of femininity, highlights the anxiety and frustration participants felt due to the narrow and traditional gendered boundaries that governed their self-expression with other men. A key observation within this theme is that nongendered activities (e.g., openness to talking, wearing a lot of cologne, and styles of dress) potentially raised questions about men's sexual orientations. Confusion about and distancing from masculinity, the fourth theme, relates to the participants' general sense of discomfort in identifying with masculinity, combined with their lack of critical thought and reflection on the issue. Davis posits: "They were simultaneously unreflective about what being a guy means and aware that masculinity was something with which they did not want to identify" (p. 516). Finally, a sense of challenge without support was identified as the fifth theme. The participants expressed a general feeling of being neglected, primarily because there were no gender-specific support services available to men that paralleled campus resources offered for women.

On a college or university campus, male gender role conflict plays itself out as men seek to compensate for certain perceived inadequacies or attempt to interact with their same-sex peers in ways that are void of emotion and closeness. Public displays of hypermasculinity, sexism, homophobia, and other exaggerated behaviors that are stereotypically male are among the manifestations of such conflict (O'Neil et al., 1986). It is important to note that gender role conflict theory suggests outward attempts to conform to narrow societal expectations of behavior are often incongruent with genuine internal desires to behave differently.

\section{Social Construction of Masculinities}

An examination of the overrepresentation of undergraduate men in campus judicial processes must consider the influence of typical patterns of masculine identity formation. Social constructivism, which is guided primarily in the work of Vygotsky (1978), provides an appropriate framework for understanding that learning is cultural, not just internal and individualistic. Accordingly, direct interactions with oth- 
ers and overall engagement in society provides context and stimuli for the juxtaposition of learned behaviors. Certain cultures tend to exist among boys and men. Thus, social constructivists would argue that traditional male behavior and attitudes such as violence, preoccupation with physical prowess, and masculine aggressiveness are learned behaviors that are produced and reinforced in social institutions and through cultural interactions (Connell, 1993; Kimmel, Hearn, \& Connell, 2005; Kimmel \& Messner, 2004; Levant, 1996; Pleck, 1981; Pollack, 2000). Male peer groups, sports, and popular culture are the three primary social institutions in which masculinity is constructed.

Homosocial peer interactions often include fellowship, camaraderie, validation, homophobia, and unhealthy expressions of masculinity (Kimmell, 1996). Homophobia is not only the discomfort of interacting with gay men or the fear of being mistaken as gay by one's peers. Kimmell explains that homophobia also includes anxiety about not measuring up to peer-approved standards of what it means to be "a real man" (p. 8). Though many are, not all behavioral manifestations of homophobia are intentional. Pressure to be perceived as masculine by peers and self causes some men to subconsciously exhibit homophobic masculine behaviors (Messner, 2001). Moreover, Connell (1993) asserts that men of all ages and ethnicities are often forced to "negotiate" their masculinities with other men-meaning their manhood must be approved and validated by their same-sex peers. Morrison and Eardley's (1985) assertions illuminate what most published literature reports on socially produced learned behaviors among males:

Boys grow up to be wary of each other. We are taught to compete with one another at school, and to struggle to prove ourselves outside it, on the street, the playground and the sports field. Later we fight for status over sexual prowess, or money, or physical strength or technical know-how. We fear to admit our weaknesses to one another, to admit our failures, our vulnerability, and we fear being called a 'sissy' or a 'softy.' The pressure is on to act tough. We fear humiliation or exclusion, or ultimately the violence of other boys if we fail to conform. (p. 19)

Morrison and Eardley also note that sports are popular vehicles for male-to-male competition. 
"Sports figure strongly into what it means to be cool and it is crucial to [boys'] need to be part of a social group" (Gilbert \& Gilbert, 1998, p. 63). Participation in sports serves a critical role in reinforcing socially constructed traditional masculine behaviors. For instance, sports allow for meaningful interaction between adolescent and adult males-usually in the absence of women. It is through this interaction that boys internalize customary male language and are acculturated to traditional male attitudes such as homophobia and the sexual objectification of women. Also, the locker room serves as both a physical and symbolic setting for this type of interaction, as male locker room jokes in high school and college are almost always about degrading women (Messner, 1992). Once internalized, these socially constructed masculine misperceptions and their corresponding behaviors are continually reinforced through social institutions and interactions, and they become a core component of the male identity.

In addition to sports-related interactions, male peer groups produce, model, police, and reinforce socially constructed masculine behaviors in other ways. Theorists frequently identify a "masculine code" (Davis, 2001; Ferguson, 2004) or a "boy code" (Pollack, 2000) that serve to reinforce socially constructed masculine behaviors among male peers. Conformity to the norm by appearing as "one of the boys" is a strategy employed within male peer groups to protect oneself from teasing or subordination (Swain, 2005). Carol Gilligan's (1982) theory suggests that empathy, emotional expression, humility, and moral reasoning are perceived as feminine traits by most men; and are grossly inconsistent with the aforementioned codes of most male peer groups. This may partially explain why some college men publicly embrace the sexist, homophobic, or violent behaviors exhibited by their peers, even when they are privately inconsistent with their own personal values and beliefs.

Furthermore, popular culture as depicted through television, film, and magazines presents media images of masculinity that serve both comparative and aspirational purposes for everyday men. Most popular images of men strive to differentiate them from women (McKay, Mikosza, \& Hutchins, 2005). Thus, portrayals of men as authoritative, powerful, tough, defiant, and sexually aggressive are commonplace in popular culture. Images of high-profile male athletes are often constructed in this regard. Finally, scholars have linked socially con- 
structed images of masculinity in popular culture to the disproportionate rates of sexual assault (Katz, 1995), violence (Hong, 2000), and alcohol and tobacco use (Capraro, 2000; Courtenay, 2004) among college men.

"Male violence represents the darkest feature of masculinity" (Brooks $\&$ Silverstein, 1995, p. 282). That college men are grossly overrepresented among the perpetrators and victims of physical assault on college and university campuses warrants serious attention. Though often male-on-male, violent acts are also committed against female students by their male counterparts. Alcohol, in more cases than not, plays a role in these occurrences (Boswell \& Spade, 1996), as drinking engenders feelings of power and sexual aggression within some men (Capraro, 2000). College men engage in this type of abusive behavior to earn the approval and respect of their same-sex peers. Most male-on-male fights escalate from verbal disputes to physical altercations. Reportedly, men are more likely to resort to physical violence as a means of resolving disputes (Gilligan, 1982). Fighting allows them to demonstrate their toughness, assert dominance over another individual, and earn the approval of their male peers; whereas alternative conflict resolution is associated with weakness, another socially constructed misperception.

\section{Developing Competence and Self-Efficacy}

Chickering (1969) and Chickering and Reisser's (1993) work presented hypotheses regarding the relationships between college experiences and environments and the psychosocial identity development of students. Those hypotheses have been tested in numerous college-impact and student development studies throughout the past 30 years (Evans, Forney, \& Guido-DiBrito, 1998). Chickering's theory includes seven vectors that contribute to identity formation, one of which is developing competence. This vector focuses on a student's perceived sense of competence regarding a certain task or goal. Chickering and Reisser suggest that competence is often developed in three areas: intellectual competence, physical and manual skills, and interpersonal competence. The third area relates most closely to the proposed theoretical model in this article. Accordingly, a sense of interpersonal competence is developed when one is able to successfully negotiate and build affirming relationships with peers. Furthermore, the ability to com- 
municate effectively with others leads to greater feelings of approval and acceptance. Thus, in order to develop higher degrees of interpersonal competence, college men often feel the need to engage in socially desirable behaviors that will presumably win the approval of their same-sex peers, even if these acts violate campus rules.

Some college men resort to a variety of unhealthy behaviors in their attempts to build interpersonal competence. For instance, a 17-yearold freshman may strive for interpersonal competence by demonstrating to his male peers that he can consume large quantities of alcohol. The same rationale may explain why some male students commit sexual assault. In accordance with traditional conceptualizations of masculinity, men gain approval from their same-sex peers by engaging in sexual activity with multiple female partners (Harper, 2004). A male college student may strive for interpersonal competence by showing his peers how capable he is of having sex with any attractive woman he desires, even if the sexual contact is nonconsensual.

Similar to the development of interpersonal competence, social interactions, acceptance, and peer influences have been shown to influence self-efficacy. Bandura's $(1977,1991,1997)$ self-efficacy theory is based on an individual's perception of his or her abilities and competencies in performing various tasks. These perceptions are typically informed by previous experiences and the positive reinforcement provided by various actors in the individual's environment. The theory also posits that recognition of competence leads to improved performance, increased motivation to repeat the task, and the development of higher related goals, even if the task is destructive in nature. Consistent with the "I can do it" spirit of self-efficacy is an assumption that "I can get away with it, like I did before," a belief typically held among repeat judicial offenders who were not previously caught or sanctioned. Peers sometime endorse and validate rule-breaking behaviors, which tends to be the case among college men, especially those who live on allmale residence hall floors and in fraternity houses (Kuh \& Arnold, 1993).

Bandura (1991) suggests that students sometimes learn "vicariously" through their peers and benchmark their abilities against other students in their campus communities, especially those with whom they have much in common. Vicarious learning, Bandura maintains, 
requires both modeling and observation. That is, one must model a certain behavior or act that is observed by the vicarious learner. The observer also learns the outcomes, benefits, and consequences associated with the behavior or act. Such vicarious observations lead students to believe that if their peers can accomplish a certain task (or get away with a certain offense), they should be able to as well. If comparable competence cannot be demonstrated, some college men look for other ways to prove their manhood, skill, and power; or their frustration is released through violent, aggressive, and antisocial behaviors.

\section{Context-Bound Gendered Social Norms}

This variable of the model concerns itself with gendered norms in the context of a particular college or university campus, as opposed to society at large. Social norms theory states that a student's behavior is influenced by misperceptions of the attitudes and/or behaviors of his or her peers (Berkowitz, 2003). The original application of the theory by Berkowitz and Perkins (1986) involved a study that analyzed patterns of student alcohol use. A key finding was that college students often overestimate the extent to which their peers are engaged in and supportive of irresponsible drinking behaviors. In addition, they also found that students often modified their own consumption levels based on this overestimation. Thus, students drank more than they personally desired primarily because they perceived their peers to be engaged in more drinking than was actually true.

Regarding social norms, Berkowitz (2004) presents three types of misperceptions. Pluralistic ignorance, the most commonly held misperception, occurs when the majority of individuals erroneously assume that their attitudes and/or behaviors are inconsistent with those of their peers, when they are in fact consistent. This misperception operates by encouraging individuals to suppress healthy attitudes and behaviors that are believed to be contradictory to the norm and to encourage unhealthy attitudes and behaviors that are falsely perceived as normative. For example, a common phenomenon among most male subgroups is to engage in sexist and homophobic joking. College men who are uncomfortable with this behavior rarely confront their peers for fear that their opinion represents the minority. 
False consensus, the second misperception, encourages an individual to incorrectly assume that there is more peer adherence to the way one thinks and acts than is actually the case (Berkowitz, 2004). This misperception functions by reinforcing an individual's belief that his or her own problematic attitudes or behaviors are normative and appropriate when they are not. An example offered by Berkowitz is that of the heavy drinker who is personally motivated to binge drink because he believes his peers are engaging in the same behavior, which enables him to justify his own heavy drinking.

Finally, the third misperception is false uniqueness, which occurs when individuals with minority attitudes or behaviors assume the difference between themselves and the majority population is greater than what is actually the case. Berkowitz offers the example of abstainers who underestimate the prevalence of abstinence among their peers. One common effect is that individuals holding this misperception selfselect out of participation in the larger community, believing that their attitudes or behaviors will be deemed unpopular by the majority. Suls and Green (2003) found that alcohol-related social norms have a stronger effect on men than on women. In addition, fraternities, athletic teams, and other influential campus subgroups play a greater role in shaping the social norms of a campus (Berkowitz, 2004).

\section{Environmental Ethos and Corresponding Behaviors}

Lewin's (1936) Interactionist Perspective provides insight into the nexus between student behaviors and the campus environment. Translated, the equation $B=f(P \times E)$ means behavior $(B)$ is a function $(f)$ of the interaction $(\mathrm{x})$ of person $(P)$ and environment $(E)$. This theoretical perspective serves as a guide for understanding how individual students' backgrounds and characteristics, coupled with environmental factors, affect their behaviors in college. Evans et al. (1998) offer the following:

Student development theories help describe the 'person' aspect of Lewin's equation . . however, we must not neglect the 'environment' side of the equation, for it is environments, in the form of physical surroundings, organizational structures, and human aggregates that present the experiences that either retard or facilitate development. (p. 25) 
A campus with a rowdy fraternity community, a big-time sports culture, and a weak judicial affairs office that rarely imposes strict sanctions on offenders will likely incite destructive behaviors among those who come to the environment already socialized to deem such behaviors excusable. Similarly, the ethos of a fraternity house may cause certain members to behave in ways they would not have even considered if they were in a different environment with a different cast of characters.

\section{Interactions among Variables}

Though described separately in the previous section, each construct of the model interacts with another to explain the overrepresentation of college men among campus judicial offenders. The precollege socialization experiences that men bring to a campus inform their assumptions regarding appropriate gender roles and behaviors. Although childhood and high school peers were not discussed as part of the precollege socialization variable, men come to college having been influenced (to varying degrees) by the three agents that tend to have the most authority in the social construction of their masculine identities: peers, parents, and popular culture, including sports. Precollege socialization experiences also affect the establishment and communication of gendered norms within the context of a particular campus. The point here is that students' past experiences and previous orientations to manhood play a major role in deciding gendered norms and facilitating the misperceptions that often ensue on a college or university campus.

Male gender role conflict also affects the social construction of masculine identities, as peers and media images help shape students' understanding of what tasks, behaviors, and attitudes are appropriately male. One's ability to resolve these conflicts results in the development of competence and high levels of self-efficacy, even if conflict resolution is achieved through peer-approved misbehavior. Unsuccessful resolution can also affect interpersonal competence and self-efficacy, as frustrated male students seek other ways to prove their manhood and skill. This is complicated by socially constructed messages about what it is men should be able to do. Campus norms are also shaped by the competencies of its actors. Specifically, messages about the skills that 
male students should possess become part of the norms for a campus, and misperceptions about exactly how many men on the campus possess those skills are often exaggerated.

It is important to acknowledge that four of the six variables influence and are influenced by the social construction of masculinities. The centrality of this construct in the model is consistent with most of the men's studies literature. Reportedly, social institutions and social interactions continually influence the ways in which society and men themselves view masculine-appropriate behaviors, skills men ought to possess, and the normative rules that should govern men when they interact in various contexts. Furthermore, these perceptions inform the ways parents, K-12 teachers, and various others socialize young boys, which becomes cyclical as boys become consumers and agents of popular culture who enroll in college and later become fathers themselves. Gendered social norms are wrought by external messages that are brought to the campus context by male students whose masculine identities have already been socially constructed and will continue to be negotiated throughout their matriculation at the institution. The gendered social norms of a campus ultimately affect environmental ethos that yield certain behaviors among men and women.

\section{Practical Implications}

In an attempt to curb the overrepresentation of men in campus judicial processes, colleges and universities must develop programmatic interventions that are designed to redefine traditional male behavior. These efforts should provide opportunities for male students to express themselves and explore their perceptions of manhood, while simultaneously exposing them to positive examples of masculinity. Gehring (2001) argues, "The disciplinary process on campuses has been too procedural and mirrors an adversarial proceeding that precludes student development" (p. 466). To this end, developmental approaches to addressing male misbehavior on college and university campuses are offered in this section. These practical recommendations are informed by the theories presented throughout this article, as well as Davis and Laker's (2004) framework for designing services for college men. 
New student orientation continues to be a prime opportunity to prepare students for their undergraduate experiences by providing valuable information and resources. Because many students come to college with perceptions rooted in popular culture, it is essential that they are given a more accurate description of environmental realities upon arrival to campus. A "men's only" orientation session led by juniors and seniors would afford incoming students the opportunity to engage peers in candid discussions about their preconceived notions of what it means to be a man in general, and a male collegian at that particular institution specifically. Allowing experienced same-sex students to challenge these assumptions and provide actual accounts of the college experience will aid incoming students in shaping accurate and realistic perceptions of the college environment.

Student affairs professionals should also make a conscious effort to showcase individual students and organizations that represent positive masculine behaviors and attitudes. The benefit of highlighting positive behavior is two-fold: (1) It rewards the individual or group exhibiting desired and productive behaviors, and (2) it exposes conflicted students to healthy role models. If campuses fail to provide positive role models and examples of healthy behaviors, students will resort to traditional stereotypes and misperceptions of manhood, which often incite acts that violate university policies.

Campus counseling centers should also consider approaches that focus on building healthy masculinities among college men. Private, individualized sessions as well as small group therapy may help male students unpack their identity issues and eliminate misperceptions of pluralistic ignorance, false consensus, and false uniqueness. Ludeman (2004) advocates a small group counseling approach with male judicial offenders led by a judicial affairs officer. The focus of these sessions should not be punitive, but instead developmental, he maintains. Similar to women's centers that exist on several college and university campuses across the country, administrators should also consider investing resources into the establishment of men's centers. These centers could provide support, information, and programming on masculinity, violence reduction, the prevention of sexual assault, healthy peer interactions, and sexual orientation, as well as offer an empowering venue for the cultivation of male friendships. If resources are not available to start this type of center, perhaps multicultural 
affairs offices could expand their purposes to include programming on gender, including men's issues.

Exploring strategies for reducing the overrepresentation of men in college judicial processes would be an exercise in futility without properly giving attention to undergraduate fraternity chapters, especially those with houses on or nearby campus. Greek-letter organizations continue to be among the most popular choices for out-of-class involvement among college men, and fraternity houses continue to be venues in which members are socialized toward certain behavioral norms (i.e., drinking). Administrators must collaborate with fraternity leaders to design and implement programs that minimize destructive behaviors and policy infractions. These initiatives should be incorporated into annual fraternity retreats and new member orientations. Advisors and administrators should find creative methods to reward fraternity chapters that experience a decrease in campus judicial violations.

Campuses alone cannot change the way male students conceptualize masculinity—student affairs professionals and other administrators must enlist the assistance of parents in this endeavor. Much of male students' masculine identity socialization stems from the promotion and reinforcement of traditional models of masculinity, which often occur at home. Student affairs professionals can assist parents in expanding their own conceptualizations of what it means to be a man and alter the messages they communicate to their college-going sons. Male students are more likely to modify their perceptions of masculinity if they are receiving consistent messages from their parents and the institution. Parents' orientation would be an ideal venue in which to introduce this topic, and perhaps a special brochure designed specifically for parents of male students might be effective.

Institutions should dedicate adequate human and financial resources to programmatic interventions designed to reduce the frequency with which male students violate university policies. These resources should not only be used to provide activities and programs, but also to train staff and faculty on effective ways to challenge and support male students. Additionally, administrators should conduct annual comprehensive analyses of campus judicial trends and disaggregate these data by gender. The information gathered will illuminate pat- 
terns in male policy violations, and may also inform future programmatic interventions. Sanctions issued for common male infractions (i.e., alcohol policy violations, physical assault, vandalism, and sexual assault) should be reviewed on a regular basis to ascertain the effectiveness of interventions. Judicial sanctions and corresponding developmental initiatives should educate students about the consequences of their behaviors; deter them from repeating the same infractions in the future; and assist them in resolving issues that may have caused the unwanted behavior, including male gender role conflict and masculine identity issues surrounding competence.

\section{Conclusion}

Many scholars have written about the quantitative overrepresentation of men among perpetrators and victims of violence and destructive behaviors (e.g., Brooks \& Silverstein, 1995; Dannells, 1997; Hong, 2000; Ludeman, 2004; Pollack, 2000). The theoretical model proposed in this article attempts to explain the overrepresentation of college men among campus judicial offenders. Grounded in several different theories from multiple academic disciplines, the model needs to be tested among contemporary college men to confirm its accuracy, completeness, and applicability to diverse populations (e.g., different racial/ethnic minority male subgroups, gay and bisexual men, and male students with physical disabilities). In addition, a study based on various constructs of the model in which data are collected from male judicial offenders to determine the gendered and environmental causes of misbehavior would be instructive.

College and university administrators and faculty aspire to create safe learning environments that facilitate students' intellectual and psychosocial development. Addressing the overrepresentation of college men among judicial offenders is clearly consistent with this goal. By understanding the interaction between the variables comprising the theoretical model presented herein, student affairs professionals will be better equipped to not only address the aggressive and sometimes violent behaviors that men exhibit, but also support male students in their total development. Ultimately, this will reduce the frequency of alcohol-related incidents, physical and sexual assaults, and other unwanted behaviors that are disproportionately committed by male 
students on college campuses, and lead to a campus environment in which healthy, nondestructive masculine identities are formed.

\section{References}

Askew, S., \& Ross, C. (1988). Boys don't cry: Boys and sexism in education. Philadelphia, PA: Open University Press.

Bandura, A. (1977). Self-efficacy: Toward a unifying theory of behavioral change. Psychological Review, 84, 191-215.

Bandura, A. (1991). Social cognitive theory of moral thought and action. In W. M. Kurtines \& J. L. Gerwitz (Eds.), Handbook of moral behavior and development (pp. 45-103). Hillsdale, NJ: Earlbaum.

Bandura, A. (1997). Self efficacy: The exercise of control. New York: W.H. Freeman.

Berkowitz, A. D. (2003). Applications of social norms theory to other health and social justice issues. In H. W. Perkins (Ed), The social norms approach to preventing school and college age substance abuse: A handbook for educators, counselors, clinicians. San Francisco: JosseyBass.

Berkowitz, A. D. (2004). An overview of the social norms approach. In L. Lederman \& L. Stewart (Eds.), Changing the culture of college drinking: A socially situated health communication campaign. Creskill, NJ: Hampton Press.

Berkowitz, A. D., \& Perkins, H. W. (1986). Resident advisers as role models: A comparison of drinking patterns of resident advisers and their peers. Journal of College Student Personnel, 27, 146-153.

Boswell, A. A., \& Spade, J. Z. (1996). Fraternities and collegiate rape culture: Why are some fraternities more dangerous places for women? Gender \& Society, 10 (2), 133-147.

Brooks, G. R., \& Silverstein, L. B. (1995). Understanding the dark side of masculinity: An interactive systems model. In R. Levant \& W. Pollack (Eds.), A new psychology of men (pp. 280-336). New York: Basic Books.

Capraro, R. L. (2000). Why college men drink: Alcohol, adventure, and the paradox of masculinity. Journal of American College Health, 48, 307-315.

Chickering, A. W. (1969). Education and identity. San Francisco: Jossey-Bass. 
Chickering, A. W., \& Reisser, L. (1993). Education and identity (2nd ed.). San Francisco: Jossey-Bass.

Connell, R. W. (1993). Disruptions: Improper masculinities. In L. Weis \& M. Fine (Eds.), Beyond silenced voices (pp. 191-208). Albany, NY: State University of New York Press.

Courtenay, W. H. (2004). Best practices for improving college men's health. In G. E. Kellom (Eds.), Developing effective programs and services for college men. New Directions for Student Services (No. 107, pp. 59-74). San Francisco: Jossey-Bass.

Dannells, M. (1997). From discipline to development: Rethinking student conduct in higher education. ASHE-ERIC Higher Education Report (Vol. 25, No. 2). Washington, DC: The George Washington University Graduate School of Education and Human Development.

Davis, J. E. (2001). Black boys at school: Negotiating masculinities and race. In R. Majors (Ed.), Educating our Black children: New directions and radical approaches (pp. 169-182). New York: RoutledgeFalmer.

Davis, T. (2002). Voices of gender role conflict: The social construction of college men's identity. Journal of College Student Development, 43 (4), 508-521.

Davis, T., \& Laker, J. A. (2004). Connecting men to academic and student affairs programs and services. In G. E. Kellom (Ed.), Developing effective programs and services for college men. New Directions for Student Services (No. 107, pp. 47-58). San Francisco: Jossey-Bass.

Evans, N. J., Forney, D. S., \& Guido-DiBrito, F. (1998). Student development in college: Theory, research, and practice. San Francisco: Jossey-Bass.

Ferguson, A. (2004). Making a name for yourself: Transgressive acts and gender performance. In M. Kimmel $\&$ M. Messner (Eds.), Men's lives (6th ed.). Boston: Allyn \& Bacon.

Gehring, D.D. (2001). The objectives of student discipline and the process that's due: Are they compatible? NASPA Journal, 38 (4), 466-481.

Gilbert, R., \& Gilbert, P. (1998). Masculinity goes to school. New York: Routledge.

Gilligan, C. (1982). In a different voice: Psychological theory and women's development. Cambridge, MA: Harvard University Press.

Good, G. E., \& Wood, P. K. (1995). Male gender role conflict, depression, and help seeking: Do college men face double jeopardy? Journal of Counseling \& Development, 74, 70-75. 
Gregory, J. F. (1996). The crime of punishment: Racial and gender disparities in the use of corporal punishment in U.S. public schools. Journal of Negro Education, 64, 454-462.

Harper, S. R. (2004). The measure of a man: Conceptualizations of masculinity among high-achieving African American male college students. Berkeley Journal of Sociology, 48 (1), 89-107.

Head, J. (1999). Understanding the boys: Issues of behaviour and achievement. London: Falmer.

Hong, L. (2000). Toward a transformed approach to prevention: Breaking the link between masculinity and violence. Journal of American College Health, 48, 269-282.

Katz, J. (1995). Reconstructing masculinity in the locker room: The Mentors in Violence Prevention Project. Harvard Educational Review, 65 (2), 163-174.

Kellom, G. E. (Ed.). (2004). Developing effective programs and services for college men. New Directions for Student Services (No. 107). San Francisco: Jossey-Bass.

Kimmell, M. (1996). Manhood in America: A cultural history. New York: Free Press.

Kimmel, M. S., \& Messner, M. A. (Eds.). (2004). Men's lives (6th ed.). Boston: Allyn \& Bacon.

Kimmel, M. S., Hearn, J., \& Connell, R. W. (Eds.). (2005). Handbook of studies on men and masculinities. Thousand Oaks, CA: Sage Publications.

Kuh, G. D., \& Arnold, J. C. (1993). Liquid bonding: A cultural analysis of the role of alcohol in fraternity pledgeship. Journal of College Student Development, 34, 327-334.

Levant, R. F. (1996). The new psychology of men. Professional Psychology: Research and Practice, 27 (3), 259-265.

Lewin, K. (1936). Principles of topological psychology. New York: McGraw-Hill.

Ludeman, R. B. (2004). Arrested emotional development: Connecting college men, emotions, and misconduct. In G.E. Kellom (Ed.), Developing effective programs for college men. New Directions for Student Services (No. 107, pp. 75-86). San Francisco: Jossey-Bass.

Mac an Ghaill, M. (1996). "What about the boys?" Schooling, class, and crisis masculinity. Sociological Review, 44 (3) 381-197.

McKay, J., Mikosza, J., \& Hutchins, B. (2005). "Gentlemen, the lunchbox has landed:" Representations of masculinities and men's bodies in the popular media. In M. Kimmel, J. Hearn, \& R. W. Connell 
(Eds.), Handbook of studies on men \& masculinities (pp. 270-288). Thousand Oaks, CA: Sage.

Messner, M.A. (1992). Power at play: Sports and the problem of masculinity. Boston, MA: Beacon Press.

Messner, M.A. (2001). Friendship, intimacy, and sexuality. In S. M. Whitehead \& F. J. Barrett (Eds.), The masculinities reader (pp. 253-265). Malden, MA: Blackwell.

Mirande, A. (2004). "Macho": Contemporary conceptions. In M. Kimmel \& M. Messner (Eds.), Men's lives (6th ed., pp. 28-38). Boston: Allyn \& Bacon.

Morrison, P., \& Eardley, T. (1985). About men. Philadelphia, PA: Open University Press.

O'Neil, J. M. (1990). Assessing men's gender role conflict. In D. Moore \& F. Leafgren (Eds.), Men in conflict: Problem solving strategies and interventions (pp. 23-38). Alexandra, VA: American Counseling Association.

O'Neil, J. M., Helms, B. J., Gable, R. K., David, L., \& Wrightsman, L., S. (1986). Gender role conflict scale: College men's fear of femininity. Sex Roles, 14 (5/6), 335-350.

O’Neil, J. M., \& Nadeau, R. A. (2004). Men's gender-role conflict, defense mechanisms, and self-protective defensive strategies. In M. Harway \& J. M. O’Neil (Eds.), What causes men's violence against women? (pp. 89-116). Thousand Oaks, CA: Sage.

Pleck, J. H. (1981). The myth of masculinity. Cambridge, MA: MIT Press.

Pollack, W. S. (2000). Real boys' voices. New York: Random House.

Rudolph, F. (1990). The American college and university: A history. Athens, GA: The University of Georgia Press.

Smith, C., \& Lloyd, B. B. (1978). Maternal behavior and perceived sex of infant. Child Development, 49, 1263-1265.

Skiba, R. J., Michael, R. S., Nardo, A. C., \& Peterson, R. L. (2002). The color of discipline: The sources of racial and gender disproportionality in school punishment. The Urban Review, 34 (4), 317-342.

Suls, J., \& Green, P. (2003). Pluralistic ignorance and college student perceptions of gender-specific alcohol norms. Health Psychology, 22 (5), 479-486.

Swain, J. (2005). Masculinities in education. In M. Kimmel, J. Hearn, \& R.W. Connell (Eds.), Handbook of studies on men \& masculinities (pp. 213-229). Thousand Oaks, CA: Sage. 
NASPA Journal, Vol. 42, no. 4

Van Kuren, N. E., \& Creamer, D. G. (1989). The conceptualization and testing of a causal model of college student disciplinary status. Journal of College Student Development, 30, 257-265.

Vygotsky, L.S. (1978) Mind and society: The development of higher psychological processes. Cambridge, MA: Harvard University Press. 